\title{
Investigation of the thermophysical properties of the oxide layer formed by microarc oxidation on Al-Si alloy
}

\author{
Natalia Yu. Dudareva ${ }^{1, *}$, Pavel V. Ivashin ${ }^{2}$, and Alexander B. Kruglov ${ }^{3}$ \\ ${ }^{1}$ Ufa State Aviation Technical University, Internal Combustion Engine Department, 450000 Karl Marx st., 12, Ufa, Russian Federation \\ ${ }^{2}$ Togliatti State University, Research department - 4, 445020 Belorusskaya st., 14, Togliatti, Russian Federation \\ ${ }^{3}$ National Research Nuclear University «MEPhI», Department of Thermal Physics, 115409 Kashirskoe shosse, 31, Moscow, Russian \\ Federation
}

\begin{abstract}
The results of the experimental study of the thermophysical properties of the coating formed by microarc oxidation (MAO) on an aluminum-silicon alloy AK12D are presented. The description of the research methodology, including the formation of the MAO-layer on the surface of laboratory samples and the study of their structure, composition and of thermophysical properties are given. The thermal conductivity of the coating was investigated by two methods: steady state and laser flash method. The tests were performed within the temperature range of $50-400^{\circ} \mathrm{C}$. The obtained results showed that the coating have a rather low thermal conductivity $\left(\lambda=1.32 \ldots 1.52 \mathrm{~W} /(\mathrm{m} \cdot \mathrm{K})\right.$ at $\left.100{ }^{\circ} \mathrm{C}\right)$. It is shown that a wealth of mullite (up to $60 \%$ ) does not lower the thermal conductivity of the coating. It is assumed that the basic factors affecting the thermal conductivity of the oxide layer are small-scale porosity, crystallite sizes and amorphous phase.
\end{abstract}

\section{Introduction}

Microarc oxidation (MAO) technology is becoming increasingly popular in the industry nowadays [1-3]. This method of coating formation is very promising for details made from $\mathrm{Al}, \mathrm{Mg}, \mathrm{Ti}, \mathrm{Ta}, \mathrm{Nb}, \mathrm{Zr}, \mathrm{Be}$ and their alloys $[4,5]$. MAO-coatings on aluminum alloys have a unique combination of the properties: high wear resistance, corrosion resistance and heat resistance [6-9].

Using of MAO-layers as thermal barrier coatings is greatly promising way of its application. The application of MAO-coatings to heated details of power equipment leads to reducing their heat stress enhances reliability and increases engine efficiency. This is very important for engine pistons, working at temperatures up to $400^{\circ} \mathrm{C}$ [10].

Application of MAO-coatings requires the knowledge of the basic thermophysical properties, such as specific heat capacity, thermal diffusivity and thermal conductivity. However, the thermophysical properties of MAO coatings are not completely investigated nowadays. Therefore, the reliable information about the thermophysical properties of MAO coating should be obtained experimentally.

\section{Formulation of the problem}

Investigation of the structure and thermophysical properties of the MAO-layers is a complex study. Therefore, the number of researches describing the thermophysical properties of MAO-layers is very insignificant nowadays.

There are a few papers, that describe the determination of the thermal conductivity of the MAO layer formed on a wrought aluminum alloy 6082 (with fraction $\mathrm{Si}$ of $0.7 \ldots 1.3 \%$ ) in a silicate-alkaline electrolyte [11-13]. The thermal conductivity of the MAO-coating depends on its composition. It was revealed in [13] that the thermal conductivity of the mullite-rich coating decreases to $\lambda=0.5 \pm 0.2 \mathrm{~W} /(\mathrm{m} \cdot \mathrm{K})$.

All the thermophysical data were obtained for the MAO-coatings formed on the wrought aluminum alloy 6082. However, in the industry, alloys with a high silicon content (Al-Si alloys) are most common. Therefore, the study of the thermophysical properties of MAO-layers formed on $\mathrm{Al}-\mathrm{Si}$ alloys is an actual challenge. This research is aimed to this problem.

\section{The Methodology of Research}

\subsection{Sample preparation}

Samples of the eutectic aluminum-silicon alloy (Russian mark is AK12D; $\mathrm{Si}-10 \ldots 13 \%, \mathrm{Fe}-1.5 \%, \mathrm{Mn}-0.5 \%$, $\mathrm{Ti}-0.1 \%, \mathrm{Cu}-0.6 \%, \mathrm{Zr}-0.1 \%, \mathrm{Mg}-0.1 \%, \mathrm{Zn}-$ $0.3 \%, \mathrm{Al}$ - balance [14]) were used.

The MAO-coating was formed on a disk, with diameter of $68 \mathrm{~mm}$ and thickness of $10 \mathrm{~mm}$. The MAOprocess was performed in a silicate-alkaline electrolyte prepared with distilled water, $\mathrm{Na}_{2} \mathrm{SiO}_{3}(2.5 \mathrm{~g} / \mathrm{l})$ and

\footnotetext{
Corresponding author: natalia_jd@mail.ru
} 
$\mathrm{KOH}(2.5 \mathrm{~g} / \mathrm{l})$. The electrical parameters of the process were: the ratio of the anodic and cathodic current was kept constant $\mathrm{Ia} / \mathrm{Ic}=1$, the average current density was $\mathrm{j}$ $=13 \pm 2 \mathrm{~A} / \mathrm{dm}^{2}$, the pulse frequency was $50 \mathrm{~Hz}$. The process took $90 \mathrm{~min}$. The electrolyte temperature did not exceed $36^{\circ} \mathrm{C}$.

Coated disk was cut into samples to measure its thickness, porosity and to analyze the structure. The sample for steady state method of thermal conductivity measurement had sizes of $45 \mathrm{~mm} \times 20 \mathrm{~mm} \times 10 \mathrm{~mm}$. The sample for laser flash method had diameter $9.9 \mathrm{~mm}$ and thickness of $1.9 \mathrm{~mm}$.

Thermophysical properties of the alloy AK12D (the heat capacity $-\mathrm{Cp}_{\mathrm{sb}}$ and the thermal conductivity $-\lambda_{\mathrm{sb}}$ ) were investigated on samples with $9.9 \mathrm{~mm}$ diameter and $1.9 \mathrm{~mm}$ thick. The coefficient of linear thermal expansion (CLTE) $-\alpha_{\mathrm{sb}}$ was studied on the sample with diameter of $6.0 \mathrm{~mm}$ and length of $25 \mathrm{~mm}$ with dilatometer DIL-402 at temperature range of $50-400{ }^{\circ} \mathrm{C}$.

MAO-layer was prepared as the powder for studies of heat capacity and phase composition.

\subsection{Thickness, porosity and density}

Scanning electronic microscope (SEM) "JEOL JSM 6390 " was used for the analysis thickness and porosity of oxide layer. Fraction of pores was calculated by the superposition of a square grid on the image of cross section structure of the coating [15]. The SEM images obtained with backscattered electron mode.

Geometrical sizes and weight of the coated sample, coating thickness and density of substrate were used for the calculations of coating density. The density of aluminum alloy was measured with a special experiment. The samples were weighted using a Mettler Toledo XPE 26 microbalance, to $\pm 2.5 \mu \mathrm{g}$ precision. The geometrical sizes of the samples were measured using a LINKS digital measuring instrument with an accuracy of $\pm 0.03 \mathrm{~mm}$.

\subsection{Phase composition}

Phase composition was investigated by Rigaku Ultima IV X-ray diffractometer, using $\mathrm{Cu}-\mathrm{K} \alpha$ radiation with $2 \Theta$ from 15 to $110^{\circ}$. MAO-layer prepared as a powder was used for XRD analysis as powders allow obtain more accurate results [16]. Quantitative phase analyzis was carried out with Rietveld method, using the Maud software.

\subsection{Thermophysical properties}

\subsubsection{Heat capacity}

Heat capacity of the MAO-layer within the temperature range of $50-400^{\circ} \mathrm{C}$ was measured using differential scanning calorimeter NETZSCH DSC 404F3 [17].

The measurements were made on the MAO-coating powder with a weight of $33.454 \mathrm{mg}$. A sapphire sample was used as the $C p$ standard. $C p$ measurement was carried out at $20^{\circ} \mathrm{C} / \mathrm{min}$ rate and isothermal hold at $400{ }^{\circ} \mathrm{C}$ during $3 \mathrm{~min}$ (the typical thermal program). Data were analyzed using the NETZSCH Proteus software.

\subsubsection{Thermal conductivity}

Steady state and laser flash methods both were used for thermal conductivity measurements. Coincidence of the results obtained with different methods increases reliability of the measurements.

Thermal diffusivity and conductivity of the coating and substrate both were determined with NETZSCH LFA 457 MicroFlash. This method determines thermal diffusivity with analysis of thermogram $\mathrm{T}(\tau)$ of surface of the samples heated by laser flash W( $\tau$ ) (Figure 1a). The shape of thermogram (Figure 1b) depends on thickness and thermal property of the sample layers.

Thermal diffusivity of the sample or the sample layer is calculated on the basis of the experimental thermogram. It is also possible to determine the heat capacity of the sample $[18,19]$. The thermal diffusivity and thermal conductivity of the layers are calculated with Proteus LFA Analysis software, which contains methods for samples with one, two or three layers [19].

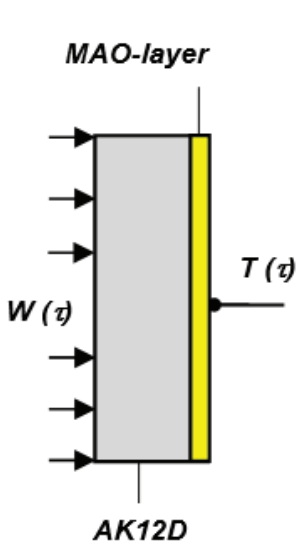

(a)

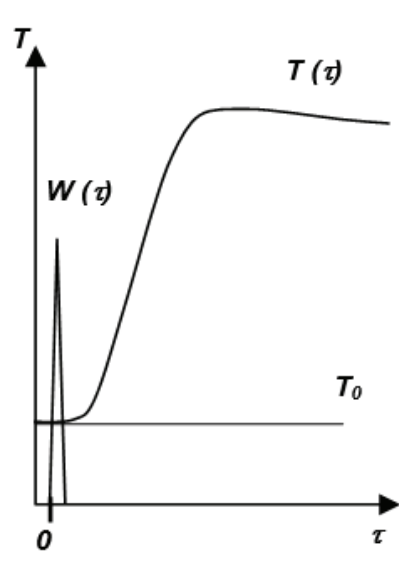

(b)
Fig. 1. Laser flash method: (a) pictorial schematic of the test, (b) thermogram.

The thermophysical properties of the AK12D alloy were determined on a sample without coating at the beginning of the experiment. The values of thermal diffusivity, heat capacity, CLTE and thermal conductivity were measured.

Thermal diffusivity both of coated and uncoated samples was measured. Thermal conductivity of MAOcoating was calculated with Proteus LFA Analysis software using thickness, density and Cp data of coating obtained in a special experiment. All the tests were performed within the temperature range of $50-400^{\circ} \mathrm{C}$.

Multiple-repeated tests revealed the following experimental errors. For substrate: $\Delta a / a \leq 3 \%$; $\Delta C p / C p \leq 5 \% ; \quad \Delta \lambda / \lambda \leq 7 \%, \quad$ for $\quad$ MAO-coating: $\Delta a / a \leq 5 \% ; \Delta \lambda / \lambda \leq 10 \%$.

Thermal conductivity of MAO-coating was also measured with steady state method [20] within 
temperature range of $50-150^{\circ} \mathrm{C}$. Scheme of experimental equipment is shown on Figure 2.

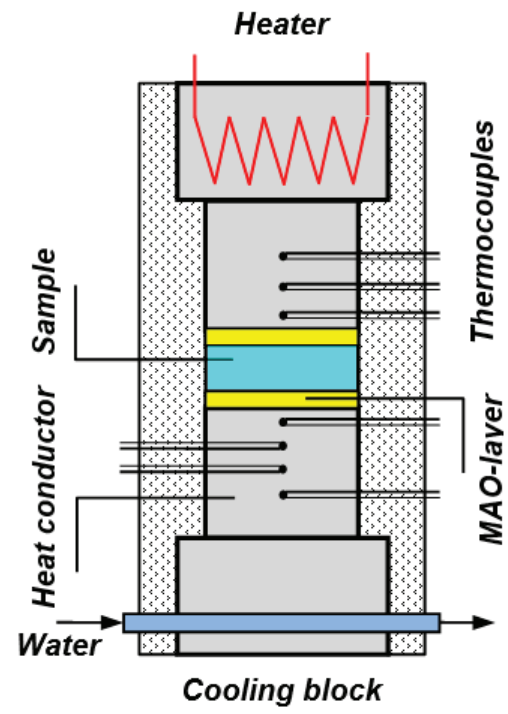

Fig. 2. Scheme of experimental equipment.

This equipment contains heater, cooler, two heat conductors, thermal insulator and four tie studs. Differential scheme of thermocouples connections was used to measurement of temperature gradient into heat conductors.

A thin layer of Arctic MX-2 thermal compound was applied on top and bottom of MAO-coated sample. Then the sample was put into measurement equipment, heater was warmed up with electrical power, cooler connected with circulated cooling water.

The signals of thermocouples were registered when thermal state of the sample and heat conductors became steady. Thermal conductivity calculated as:

$$
\lambda_{\mathrm{c}}=2 \delta_{\mathrm{c}}\left[\left(\Delta T_{\mathrm{sm}} / q\right)-\left(\delta_{\mathrm{sb}} / \lambda_{\mathrm{sb}}\right)-2 r_{\mathrm{t}}\right]^{-1}
$$

where $\lambda_{c}-$ thermal conductivity of MAO-coating; $\delta_{c}-$ MAO-coating thickness; $q-$ heat flux; $\Delta T_{\mathrm{sm}}-$ the difference between temperatures of heater and cooler surfaces connected with the sample; $\lambda_{\mathrm{sb}}-$ thermal conductivity of substrate, $\delta_{\mathrm{sb}}-$ substrate thickness; $r_{\mathrm{t}}-$ thermal resistance between sample surface and heat conductor surface.

Heat flux $q$ and $\Delta T_{\mathrm{sm}}$ were calculated by temperatures measured in heat conductors. $\lambda_{\mathrm{sb}}-$ was preliminary determined with the laser flash method. Thermal resistance $r_{\mathrm{t}}$ was determined in special experiments during repeatable measurements on samples made of copper and aluminum. Value obtained in this experiment is $r_{\mathrm{t}}=(1.8 \pm 0.2) \cdot 10^{-5}\left(\mathrm{~m}^{2} \cdot \mathrm{K}\right) / \mathrm{W}$.

Calibration of steady state experimental equipment was made by repeatable tests on the sample made of stainless steel. Thermal conductivity of this steel is exactly known [21]. Uncertainties of thermal conductivity measurements with steady state method revealed in calibration experiment are less than $15 \%$ within temperature range of $50-150^{\circ} \mathrm{C}$.

\section{Experimental results}

The transverse section of the sample, on which the thickness and porosity were measured, is shown in Figure 3.

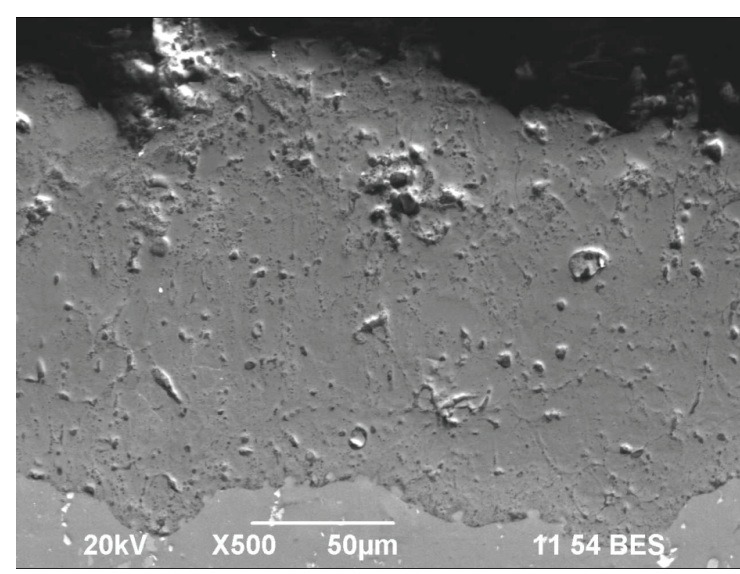

Fig. 3. Transverse section of the coating.

Studies of the macrostructure of the oxide layer showed that the average thickness of the MAO-coating is 154.1 $\pm 3.7 \mu \mathrm{m}$. The through and closed pores are present in the structure of the coating. The average porosity is $13.1 \pm 1.6 \%$.

The density of aluminum alloy AK12D determined in this study is $2679 \pm 4 \mathrm{~kg} / \mathrm{m}^{3}$. The density of the MAOcoating is $2659 \pm 565 \mathrm{~kg} / \mathrm{m}^{3}$.

The following phases were identified by the X-ray diffraction analysis of the MAO layer: $\alpha-\mathrm{Al}_{2} \mathrm{O}_{3}, \gamma$ $\mathrm{Al}_{2} \mathrm{O}_{3}, 3 \mathrm{Al}_{2} \mathrm{O}_{3} \cdot 2 \mathrm{SiO}_{2}$ (mullite), $\mathrm{Al}_{2} \mathrm{SiO}_{5}$ (sillimanite) $[22,23]$. Phase composition of the MAO-coating is shown in Figure 4:

- $\alpha-\mathrm{Al}_{2} \mathrm{O}_{3}$ (corundum) $-5.3 \pm 0.1 \%$

- $\gamma-\mathrm{Al}_{2} \mathrm{O}_{3}-34.8 \pm 1.8 \%$

- $3 \mathrm{Al}_{2} \mathrm{O}_{3} \cdot 2 \mathrm{SiO}_{2}$ (mullite) - 58.1 $\pm 2.8 \%$

- $\mathrm{Al}_{2} \mathrm{SiO}_{5}$ (sillimanite) $-1.8 \pm 0.3 \%$.

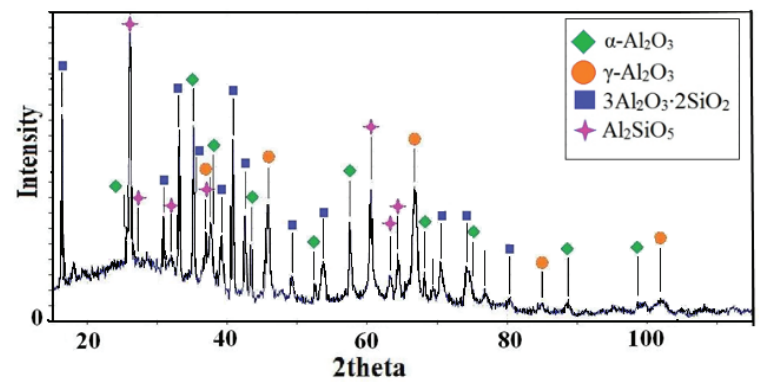

Fig. 4. Phase composition of MAO-coating.

The equations of the CLTE, heat capacity, thermal diffusivity and thermal conductivity of AK12D alloy were obtained as the result of thermophysical studies by the laser flash method:

$$
\begin{gathered}
\alpha_{\mathrm{sb}}=(0.00841 \cdot t+20.45) \cdot 10^{-6} \\
C p_{\mathrm{sb}}=808.4+0.4583 \cdot t \\
a_{s b}=(-0.0302 \cdot t+74.05) \cdot 10^{-6}
\end{gathered}
$$




$$
\lambda_{s b}=0,009 \cdot t+161,6
$$

where $\alpha_{s b}$ - the coefficient of linear thermal expansion, $\mathrm{K}^{-1} ; C p_{\mathrm{sb}}-$ the heat capacity, $\mathrm{J} /(\mathrm{kg} \cdot \mathrm{K}) ; a_{s b}-$ thermal diffusivity, $\mathrm{m}^{2} / \mathrm{s}, \lambda_{\mathrm{sb}}-$ the thermal conductivity, $\mathrm{W} /(\mathrm{m} \cdot \mathrm{K}), t$ - the temperature, ${ }^{\circ} \mathrm{C}$.

The effect of temperature on the heat capacity of the MAO layer was found:

$$
C p_{\mathrm{c}}=830.82+1.0289 \cdot t-0.0013 \cdot t^{2}
$$

Dependences of thermal diffusivity $\left(a_{\mathrm{c}}\right)$ and thermal conductivity $\left(\lambda_{c}\right)$ of the MAO-coating on the temperature revealed by the laser flash method can be described as:

$$
\begin{aligned}
& a_{\mathrm{c}}=1,198 \cdot t^{-0,1385} \cdot 10^{-6} \\
& \lambda_{\mathrm{c}}=0,0002 \cdot t+1,5132
\end{aligned}
$$

Thermal conductivity of MAO-coating obtained by the steady-state method:

$$
\lambda_{\mathrm{c}}{ }^{\prime}=0,0017 \cdot t+1,1503
$$

Thus, the thermal conductivity of the MAO-coating at $100^{\circ} \mathrm{C}$ obtained by the laser flash method is $\lambda_{\mathrm{c}}=1.52 \pm 0.34 \mathrm{~W} /(\mathrm{m} \cdot \mathrm{K})$. The thermal conductivity determined by the steady-state method, is $\lambda_{\mathrm{c}}{ }^{\prime}=1.32 \pm 0.15 \mathrm{~W} /(\mathrm{m} \cdot \mathrm{K})$ also at $100^{\circ} \mathrm{C}$.

\section{The discussion of the results}

MAO-layer formed in this study contains a large fraction of mullite (about $60 \%$ ). Based on the paper [13], where the mullite content was $50 \%$ and the porosity was about $10 \%$, it was expected that the thermal conductivity of the MAO-layer would be $\sim 0.5 \mathrm{~W} /(\mathrm{m} \cdot \mathrm{K})$. However, the independent thermophysical studies, carried out by two different methods, have shown that the coating has higher thermal conductivity: $\lambda_{\mathrm{c}}=1.32 \ldots 1.52 \mathrm{~W} /(\mathrm{m} \cdot \mathrm{K})$ at $100{ }^{\circ} \mathrm{C}$. Thus, it can be concluded that the influence of mullite on thermal conductivity of the coating is not so significant as it expected.

It should be noted that the registered thermal conductivity of the oxide layer is lower than thermal conductivity of dense mullite $(\sim 10-15 \mathrm{~W} /(\mathrm{m} \cdot \mathrm{K}))$, dense sillimanite $(\sim 9.1 \mathrm{~W} /(\mathrm{m} \cdot \mathrm{K}))$, and dense aluminum oxide $(\sim 34.6 \mathrm{~W} /(\mathrm{m} \cdot \mathrm{K}))$ [24]. This fact can be explained if we suppose that the thermal conductivity of MAO-layer does not depend on the mullite volume, but depends on other factors: the crystallites size, the small-scale porosity and the fraction of the amorphous phase.

\section{Conclusions}

MAO-coating formed on the Al-Si alloy in the silicatealkaline electrolyte has a high volume of mullite $(\sim 60 \%)$ and high level of porosity $(\sim 13 \%)$. The coating is characterized by large thickness of $\sim 150 \mu \mathrm{m}$ and a low density - $2659 \pm 565 \mathrm{~kg} / \mathrm{m}^{3}$.

Thermal conductivity of a mullite-rich oxide coating is $\lambda_{\mathrm{c}}=1.32 \ldots 1.52 \mathrm{~W} /(\mathrm{m} \cdot \mathrm{K})$ at $100^{\circ} \mathrm{C}$. This value is significantly lower than thermal conductivity of the phases composing of the coating, but higher than in known studies, where the oxide layer also has a high volume of mullite.

The results of this work can be useful for thermal calculations when using the MAO-coating as thermal barrier for details of heat-stressed equipment.

This work has been partially performed with support of State Research Engineering Assignment (Project 11.3937.2017/PCh).

\section{References}

1. A.L. Yerokhin, X. Nie, A. Leyland, A. Matthews, S.J. Dowey, Surf. Coat. Technol, 122, 73 (1999)

2. A.L. Yerokhin, L.O. Snizhko, N.L. Gurevina, A. Leyland, A. Pilkington, A. Matthews, Surf. Coat. Technol. 177 -178, 779 (2004)

3. Y.J. Liu, J.Y. Xu,W. Lin, C. Gao, J.C. Zhang and X.H. Chen, Rev.Adv. Mater. Sci. 33, 126 (2013)

4. R.O. Hussein, D.O. Northwood, X. Nie, Mater. Sci. and Applic. 5, 124 (2014)

5. V.A. Koshuro, G.G. Nechaev, A.V. Lyasnikova, Techn. Phys, 10, 1570 (2014).

6. A.L. Yerokhin, A.A. Voevodin, V.V. Lyubimov, J. Zabinski, M. Donley, Surf. Coat. Technol. 110, 140 (1998)

7. J. Baxi, P. Kar, H. Liang, A. Polat, M. Usta, A.H. Ucisikc, Vacuum, 83, 217 (2009)

8. P.B. Srinivasan, R. Zettler, C. Blawert, W. Dietzel, Material scharacterization, 60, 389 (2009)

9. L.R. Krishna, K.R. Somaraju, G. Sundararajan, Surf. Coat. Technol. 163 -164, 484 (2003)

10. N.Yu. Dudareva, O.P. Dombrovskiy, R.V. Kalschikov, I.A. Butusov, J. of Engineering Sci. and Technol. Rev. 6, 10 (2015)

11. J.A. Curran, Thermal and mechanical properties of plasma electrolytic oxide coatings (Cambridge, 2006)

12. J.A. Curran, T.W. Clyne, Surf. Coat. Technol. 183, 177 (2005)

13. J.A. Curran, H. Kalkanc1, Yu. Magurova, T.W. Clyne, Surf. Coat. Technol. 201, 8683 (2007)

14. Information on http://www.splav-kharkov.com.

15. S.A. Saltykov, Stereometric metallography (Moscow, Metallurgy, 1970) (in Russian)

16. R. Das, Md. E. Ali, Sh. B. Hamid, Rev. Adv. Mater. Sci. 38, 95 (2014)

17. P.J. Haines, F.W. Wilburn, in: P.J. Haines (Ed.), Thermal Methods of Analysis: Principles, Applications and Problems (London, 1995)

18. W.J. Parker, R.J. Jenkins, C.P. Butler, G.L. Abbott. J. of Appl. Phys.. 32, 1679 (1961)

19. Information on http://www.netzsch.com 
20. J.H. Lienhard IV, J.H. Lienhard V, A Heat Transfer Textbook (Cambridge, Massachusetts, 2017)

21. Tables of standard reference data. Moskow (Standard Publishing House, 1994) (in Russian)

22. V. Dehnavi, X.Y. Liu, B.Li Luan, D.W. Shoesmith, S. Rohan, Surf. Coat. Technol. 251, 106-114 (2014)

23. Z.C. Oter, A.E. Gulec, Y. Gencer, M. Tarakci, Acta phys. polonica, 4, 1331 (2015)

24. J.F. Shackelford, R.H. Doremus, Ceramic and Glass Materials. Structure, Properties and Processing (Springer, 2008) 